\title{
MICROBIOTA CONJUNTIVAL EM CÃES CLINICAMENTE SADIOS E CÃES COM CERATOCONJUNTIVITE SECA
}

\author{
ARianne Pontes Oria ${ }^{1}$, Melissa Hanzen Pinna ${ }^{1}$, MiUcha Almeida FurtadoO ${ }^{2}$, ANa Carla \\ OLIVEIRA PINHEIRO ${ }^{3}$, DEUSDETE CONCEICAO GOMES JUNIOR ${ }^{4}$, JOAO MOREIRA COSTA NeTO ${ }^{1}$ \\ ${ }^{1}$ Professores Doutores da Universidade Federal da Bahia, Salvador, BA, Brasil. arianneoria@ufba.br \\ ${ }^{2}$ Médica Veterinária da Universidade Federal da Bahia, Salvador, BA, Brasil. \\ ${ }^{3}$ Graduada em Medicina Veterinária pela Universidade Federal da Bahia, Salvador, BA, Brasil. \\ ${ }^{4}$ Pós-Graduando da Universidade Federal da Bahia, Salvador, BA, Brasil.
}

\begin{abstract}
Este trabalho objetivou determinar os microrganismos bacterianos no saco conjuntival de cães clinicamente normais e cães com ceratoconjuntivite seca (CCS), atendidos no Hospital de Medicina Veterinária da Universidade Federal da Bahia. Foram incluídos na pesquisa 30 animais sadios e 28 com CCS. Foi observado crescimento bacteriano em $60 \%$ das amostras oculares dos cães sadios e em 89,29\% dos cães com CCS. Houve predomínio de espécies Gram positivas em ambos os grupos. Nos animais normais as bactérias mais prevalentes foram Staphylococcus intermedius (26,83\%), seguido por Staphylococcus aureus (21,95\%) e Staphylococcus
\end{abstract}

epidermidis $(19,51 \%)$. Houve identificação de leveduras em 38,34\% das amostras. Dos 30 animais sadios estudados, $46,66 \%$ apresentaram cultura positiva bilateral, $26,67 \%$ cultura positiva unilateral e $26,67 \%$ cultura negativa. Nos animais com CCS, as bactérias de maior prevalência foram o Streptococcus $\beta$-hemolítico (16,13\%), seguido por Staphylococcus intermedius $(12,90 \%)$ e o Staphylococcus aureus $(11,83 \%)$. Ocorreu identificação de leveduras em 19,64\% das amostras. Dos 28 animais com CCS, observou-se que $82,14 \%$ apresentaram cultura positiva bilateral e $17,86 \%$ cultura positiva unilateral.

PALAVRAS-CHAVE: Ceratoconjuntivite seca; cão; flora conjuntival.

\section{CONJUNCTIVAL MICROBIOTA IN CLINICALLY HEALTHY DOGS AND DOGS WITH KERATOCONJUNCTIVITIS SICCA}

\section{ABSTRACT}

This study aimed to determine the bacterial microorganisms in the conjunctival sac of clinically normal dogs and of dogs with keratoconjunctivitis sicca (KCS) attended at the Veterinary Hospital of the Federal University of Bahia. Thirty health animals and 28 with $\mathrm{KCS}$ were included in the research. Bacterial growth was observed in $60 \%$ of the healthy dogs and in $89.29 \%$ of the dogs with KCS. There was a predominance of Grampositive species in both groups. In normal animals, Staphylococcus intermedius (26.83\%), followed by Staphylococcus aureus (21.95\%) and Staphylococcus epidermidis $(19.51 \%)$ were the most prevalent bacteria and the identification of yeasts in the samples of this group was $38.34 \%$. Of the 30 healthy animals studied, $46.66 \%$ showed bilateral positive culture, $26.67 \%$ had unilateral positive culture and $26.67 \%$ had negative culture. In animals with KCS, Streptococcus $\beta$-hemolytic $(16.13 \%)$, followed by Staphylococcus intermedius $(12.90 \%)$ and Staphylococcus aureus $(11.83 \%)$ were the most prevalent bacteria. Yeast identification in this group occurred in $19.64 \%$ of the samples. Of the 28 animals with $\mathrm{KCS}, 82.14 \%$ showed bilateral positive culture and $17.86 \%$ unilateral positive culture.

KEYWORDS: Conjunctival flora; dog; keratoconjunctivitis sicca. 


\section{INTRODUÇÃO}

A microbiota conjuntival normal é composta por bactérias e fungos que desempenham importante papel na estimulação da resposta imune local (MOELLER et al., 2005), na secreção de substâncias com propriedades antimicrobianas e no mecanismo competitivo entre microrganismos. A microbiota residente age como importante mecanismo de defesa (WANG, 2008) associada à secreção contínua da lágrima, a qual contém fatores limitadores do crescimento microbiano. Tais microrganismos estabelecem relação única com o hospedeiro, que se inicia à medida que o feto microbiologicamente estéril atravessa o canal do nascimento (UESUGUI et al., 2002; PRADO et al., 2005).

Indivíduos sadios suportam uma pequena população bacteriana nos olhos (GRAHAM et al., 2007), estando presentes, principalmente, as bactérias Gram positivas, com perfil que varia constantemente no tipo e frequência devido à localização geográfica, técnica de cultivo, contato com outros animais, densidade populacional e estações do ano (TUNTIVANICH et al., 2002; PRADO et al., 2005; SWINGER et al., 2009).

Quando o cão sofre uma injúria externa, a depender do grau e intensidade do trauma, desencadeiam-se processos inflamatórios superficiais na córnea e conjuntiva. Diante da perda de integridade do epitélio, bactérias e fungos podem instalar-se de forma oportunista, colonizando o ambiente (ARMSTRONG, 2000).

A ceratoconjuntivite seca é uma enfermidade caracterizada por inflamação crônica das glândulas lacrimais, córnea e conjuntiva, que decorre de alterações quali-quantitativas do filme lacrimal pré-corneano. Contudo, dados relativos à composição da microbiota conjuntival em cães com essa afecção são pouco explorados. Desta forma, objetivou-se analisar a microbiota conjuntival em cães sadios e com ceratoconjuntivite seca, atendidos no Serviço de Oftalmologia do Hospital de Medicina Veterinária da Universidade Federal da Bahia.

\section{MATERIAL E MÉTODOS}

Os protocolos de pesquisa foram aprovados pelo Comitê de Ética no Uso de Animais da Escola de Medicina Veterinária e
Zootecnia da Universidade Federal da Bahia sob $\mathrm{n}^{\circ} .24$.

Foram obtidas amostras oculares de ambos os olhos de 30 cães clinicamente saudáveis e 28 cães portadores de ceratoconjuntivite seca (CCS) de diversas raças e de ambos os sexos, oriundos dos casos atendidos no Hospital Veterinário Professor Renato Rodemburg de Medeiros Neto, da Escola de Medicina Veterinária e Zootecnia da UFBA. As avaliações e amostras foram realizadas durante o período de 18 meses (de março de 2009 a março de 2010 nos animais com CCS e de julho de 2010 a março de 2011 nos animais saudáveis). Os animais foram avaliados objetivando-se utilizar indivíduos em condições padronizadas. Para tanto, seguiu-se a semiotécnica clínica e oftálmica rotineira, notadamente os testes convencionais para mensuração da produção lacrimal e a prova da fluoresceína. Nenhum dos cães estava recebendo tratamento antimicrobiano sistêmico ou tópico antes da coleta das amostras.

Os cães clinicamente saudáveis apresentaram produção lacrimal, ao teste de Schirmer, dentro da normalidade, com média de 20,27 $\pm 2,23 \mathrm{~mm}$ e ausência de lesões oculares ou em anexos. Os cães diagnosticados com ceratoconjuntivite seca (CCS) apresentaram produção lacrimal média de $3,51 \pm 2,97 \mathrm{~mm}$ com quadros oftálmicos variados com presença de pelo menos um dos sinais característicos da CCS (pigmentação, vascularização e ulceração corneana, hiperemia conjuntival, secreção variando de mucoide a mucupurulenta, blefarite periocular).

Com o paciente contido fisicamente, foi realizado o teste de Schirmer (Ophthalmos, Ribeirão Preto, São Paulo 14020-040, Brasil), seguido da colheita das amostras para cultura, com auxílio de swabs de algodão hidrófilo estéril. Os swabs foram pressionados direta e levemente no saco conjuntival inferior de cada olho, através de movimentos rotatórios; em seguida, foram armazenados em tubos de ensaio com meio de transporte ágar triptose e mantidos sob refrigeração para posterior processamento no Laboratório de Bacterioses da Escola de Medicina Veterinária e Zootecnia da Universidade Federal da Bahia, quando foi dado prosseguimento à semiotécnica oftálmica.

As amostras foram semeadas em Agar sangue de carneiro a 6\%, Agar MacConkey e 
Caldo Triptose, incubadas a $37{ }^{\circ} \mathrm{C}$ por $24-48$ horas. Realizou-se, também, a confecção de esfregaços corados segundo a técnica de Rosenfeld para identificação de leveduras. Após o crescimento, as colônias foram identificadas tendo por base a presença ou não de hemólise em Agar Sangue, características morfológicas, tintoriais e bioquímicas de acordo com técnicas rotineiras de laboratório.

\section{RESULTADOS E DISCUSSÃO}

Os microorganismos isolados e as suas respectivas frequências encontram-se arrolados nas tabelas 1 e 2 .

Tabela 1. Bactérias isoladas do saco conjuntival de 30 cães saudáveis e 28 cães portadores de CCS

\begin{tabular}{lccccc}
\hline & \multicolumn{2}{c}{ Cães saudáveis } & & \multicolumn{2}{c}{ Cães com CCS } \\
\cline { 2 - 3 } \cline { 5 - 6 } Isolamento de microrganismos & Frequência & $\%$ & & Frequência & $\%$ \\
\hline Streptococcus $\beta$-hemolítico & 0 & 0 & & 15 & 16,13 \\
Staphylococcus intermedius & 11 & 26,83 & & 12 & 12,90 \\
Staphylococcus aureus & 9 & 21,95 & & 11 & 11,83 \\
Staphylococcus sp. & 1 & 2,44 & & 7 & 7,53 \\
Difteróides & 3 & 7,32 & & 7 & 7,53 \\
Staphylococcus epidermidis & 8 & 19,51 & & 5 & 5,73 \\
Bacillus sp. & 6 & 14,63 & & 2 & 2,16 \\
Micrococcus & 0 & 0 & & 1 & 1,07 \\
Escherichia coli & 0 & 0 & & 9 & 9,67 \\
Pseudomonas aeruginosa & 0 & 0 & & 8 & 8,60 \\
Pseudomonas spp. & 3 & 4,88 & & 0 & 0 \\
Enterobacter spp. & 0 & 0 & & 6 & 6,46 \\
Klebsiella & 0 & 0 & & 4 & 4,30 \\
Enterobacter hafnia & 1 & 2,44 & & 3 & 3,22 \\
Proteus vulgaris & 0 & 0 & & 2 & 2,16 \\
Proteus mirabilis & 0 & 0 & & 1 & 1,07 \\
Total de crescimento & 41 & 100 & & 93 & 100 \\
\hline
\end{tabular}

Tabela 2. Frequência de isolamento de leveduras no saco conjuntival de 30 cães saudáveis e 28 cães portadores de CCS

\begin{tabular}{lcccccc}
\hline & \multicolumn{2}{c}{ Cães saudáveis } & & \multicolumn{2}{c}{ Cães com CCS } \\
\cline { 2 - 3 } \cline { 5 - 6 } Isolamento de leveduras & Frequência & $\%$ & & Frequência & $\%$ \\
\hline Presença de levedura & 23 & 38,34 & & 11 & 19,64 \\
Ausência de levedura & 37 & 61,66 & & 45 & 80,36 \\
Total de amostras & 60 & 100 & & 56 & 100 \\
\hline
\end{tabular}

Nos animais sadios foi identificado crescimento bacteriano em $60 \%$ das amostras oculares (36/60), sendo evidenciado crescimento de espécies Gram positivas em 85,37\% das amostras analisadas e de bactérias Gram negativas em 14,63\%. Dentre os microrganismos Gram positivos isolados, houve predomínio de Staphylococcus intermedius (31,43\%), Staphylococcus aureus $(25,71 \%)$ e Staphylococcus epidermidis (22,86\%). Em relação ao isolamento de bactérias Gram negativas, identificaram-se Difteróides em 50\% das amostras, Pseudomonas spp. em 33,33\% e Enterobacter harfinia em 16,67\%. As bactérias mais prevalentes foram Staphylococcus intermedius com 26,83\% (11/60), seguido por Staphylococcus aureus, encontrado em 21,95\% (9/60) das amostras de conjuntiva, e Staphylococcus epidermidis isolado em 19,51\% (8/60). Bacillus spp., Difteróides, Pseudomonas spp., Streptococcus spp. e Enterobacter harfinia estavam presentes em 14,63\% (6/60), 7,32\% (3/60), 4,88\% (2/60), 2,44\% (1/60) e $2,44 \%(1 / 60)$ dos isolamentos, respectivamente. A 
identificação de leveduras nas amostras foi em $38,34 \%$ (23/60). Em 86,11\% (31/36) das amostras foi isolado apenas um único tipo de bactéria, enquanto $13,89 \%(5 / 36)$ apresentaram dois tipos bacterianos nas culturas. Dos 30 animais sadios estudados, 46,66\% apresentaram cultura positiva bilateral, $26,67 \%$ cultura positiva unilateral e $26,67 \%$ culturas negativas.

Nos animais com CCS, foi identificado crescimento bacteriano em 89,29\% das amostras oculares (50/56), sendo evidenciado crescimento de espécies Gram positivas em $64,51 \%$ das amostras analisadas e bactérias Gram negativas em 35,48\% (Tabela 2). Dentre os microrganismos Gram positivos isolados, houve predomínio de Streptococcus $\beta$-hemolítico (25\%), Staphylococcus intermedius (20\%) e Staphylococcus aureus $(18,33 \%)$. Em relação ao isolamento de bactérias Gram negativas, identificaram-se Escherichia coli (27,27\%), Pseudomonas aeruginosa (24,24\%) e Enterobacter spp. (18,18\%). As bactérias de maior prevalência foram o Streptococcus $\beta$-hemolítico com $16,13 \%$, seguido por Staphylococcus intermedius em $12,90 \%$ e o Staphylococcus aureus em 11,83\% dos isolados. Ocorreu identificação de leveduras em 19,64\% (11/56) das amostras. Em 50\% (14/28) das amostras houve crescimento bacteriano misto (Gram negativas e Gram positivas). Em 42,86\% (12/28) das amostras analisadas foi evidenciado crescimento apenas de espécies Gram positivas e em 7,14\% (2/28) apenas Gram negativas. Dos 28 animais com CCS, $50 \%$ apresentaram exclusivamente ceratoconjuntivite seca bilateral, nove $(32,14 \%)$ apresentaram doença sistêmica associada como cinomose e/ou erliquiose e cinco $(17,86 \%)$ tinham outra oftalmopatia associada, como úlcera de córnea e/ou uveíte. Nas amostras analisadas, observou-se que $82,14 \%(23 / 28)$ apresentaram cultura positiva bilateral, $17,86 \%(5 / 28)$ cultura positiva unilateral e nenhuma apresentou cultura negativa.

Os resultados obtidos com as amostras dos animais sadios confirmam os achados de HAGHKHAH et al. (2005), que identificaram 65\% de positividade nas culturas, e os de KUDIRKIENE et al. (2006), que encontraram $69 \%$ de crescimento bacteriano, sendo ambos os achados provenientes de espécimes clínicos de conjuntiva ocular de cães sadios. Entretanto, PRADO et al. (2005) obtiveram crescimento microbiano em 39\% das amostras provenientes de conjuntiva ocular de cães sadios e WANG et al. (2008), 45\% de isolados positivos. Cabe ressaltar que alguns fatores podem contribuir para a modificação dos percentuais, tais como o método de colheita, de cultivo e o tipo de swab utilizado (ANDRADE et al., 2002; PRADO et al., 2005).
Os resultados obtidos com as amostras dos animais com CCS são semelhantes aos encontrados por JONES (1955), que obteve $89,65 \%$ de crescimento positivo quando estudou a microbiota conjuntival de 29 cães acometidos por alterações oftálmicas. Resultados similares foram verificados por SANTOS et al. (2009), que obtiveram isolamento positivo em $100 \%$ das amostras cultivadas.

Cães com CCS apresentam deficiência de filme lacrimal, seja na produção ou na maior evaporação, consequentemente, há diminuição nas enzimas antibacterianas (lactoferrina, lisozima e peroxidase), situação que favorece o crescimento de bactérias no saco conjuntival, contribuindo para maior frequência de culturas positivas em relação a trabalhos realizados com cães sadios (PRADO et al., 2006), o que pode justificar os resultados encontrados.

A predominância de bactérias Gram positivas em relação às bactérias Gram negativas, encontrada nas amostras, já havia sido descrita na espécie canina por diversos autores, dentre os quais PRADO et al., (2005) e WANG et al. (2008), que encontraram, respectivamente, $86,5 \%$ e $66,7 \%$ de isolados Gram positivos. De acordo com COSTA et al. (1989), HAGHKHAH et al. (2005) e KUDIRKIENE et al. (2006), houve predomínio de isolados Gram positivos em seus respectivos estudos envolvendo microbiota normal de cães saudáveis. Esse predomínio deve-se ao achado de grande quantidade de Staphylococcus nas amostras, bactérias Gram positivas que fazem parte da microflora normal de mucosa e pele (HOEKSTRA \& PAULTON, 2002). No que se refere à espécie bacteriana predominante nos cães normais, Staphylococcus intermedius foi a bactéria mais comumente isolada, enquanto que nos cães com CCS o Streptococcus $\beta$-hemolítico foi o mais encontrado. PRADO et al. (2005) e WANG et al. (2008) encontraram Staphylococcus epidermidis e COSTA et al. (1989), HAGHKHAH et al. (2005) e KUDIRKIENE et al. (2006) identificaram Staphylococcus aureus nas amostras de conjuntiva de seus respectivos trabalhos.

Staphylococcus aureus, Staphylococcus intermedius, Staphylococcus epidermidis são agentes saprófitas da microbiota da pele de cães e foram identificados tanto nos pacientes sadios quanto nos com CCS, fato observado também por ANDRADE et al. (2002).

As espécies bacterianas isoladas em ambos os grupos estão de acordo com os achados de COSTA et al. (1989), ANDRADE et al. (2002), PRADO et al. (2005) e KUDIRKIENE et al. (2006), que isolaram, como parte da microbiota residente, 
Enterobacter agglomerans $(4,70 \%)$ e Enterobacter aerogenes (2,36\%); Enterobacter cloacae (5,26\%); Enterobacter cloacae $(5,1 \%)$ e Enterobacter spp. $(5,3 \%)$, respectivamente. Apenas a Enterobacter harfinia $(14,63 \%)$ não havia sido citada na literatura consultada.

Microrganismos do gênero Pseudomonas são encontrados como saprófitas no meio ambiente, especialmente no solo e na água, e representam importante causa de ceratite em pequenos animais; contudo, também podem ser encontrados na microbiota normal (KUDIRKIENE et al., 2006). Quando ocorrem alterações nos mecanismos de defesa da superfície ocular, tais bactérias podem expandir-se e desenvolver infecções com produção de doença (WANG et al., 2008).

De acordo com ANDRADE et al. (2002) a presença de leveduras encontrada nas amostras pode estar relacionada com as altas temperaturas que são registradas na região da realização do estudo.

As bactérias do gênero Klebsiella são enterobactérias patogênicas e importantes em humanos e animais, habitantes da flora intestinal de diversas espécies, sendo o agente causal de enterites e infecções do trato respiratório superior e/ou inferior, meningites e infecções do trato urinário em jovens e adultos (GALERA et al., 2002). Elas estavam presentes em $12,12 \%$ das amostras dos cães com CCS mais debilitados, que não se locomoviam mais e ficavam em ambientes sujos, sem sinais de cuidados higiênicos.

Em 50\% dos animais avaliados com afecções oculares foram observadas doenças sistêmicas, sendo cinomose e erliquiose as mais comuns. De acordo com BRITO et al. (1998), essas doenças são responsáveis pelo comprometimento da imunidade do animal e, consequentemente, pela instalação de várias doenças oportunistas, incluindo as complicações oculares.

\section{CONCLUSÃO}

O crescimento bacteriano proveniente de saco conjuntival de cães clinicamente sadios foi evidente, sendo que as bactérias Gram positivas apresentaram maior ocorrência dentre os isolados. Em relação às bactérias, Staphylococcus intermedius e Difiteróides foram as identificadas com maior frequência nos animais saudáveis, enquanto que Streptococcus $\beta$-hemolítico e Escherichia coli foram as identificadas com maior frequência nos animais com CCS, respectivamente, Gram positivas e Gram negativas.

\section{REFERÊNCIAS}

ANDRADE, A. L.; STRINGHINI, G.; BONELLO, F. L.; MARINHO, M.; PERRI, S. H. V. Microbiota conjuntival de cães da cidade de Araçatuba - SP. Arquivo Brasileiro de Oftalmologia, v. 65, n. 3, p. 323-336, 2002.

ARMSTRONG, R. A. The microbiology of the eye. Ophthalmology Physiology Optics, v. 20, n. 6, p. 429441, 2000.

BRITO, F. L. C.; ALVES, L. C.; LAUS, J. L. Manifestações oculares na leishmaniose visceral canina revisão. Revista Clínica Veterinária, n. 64, p. 68-74, 1998.

COSTA, M.; CARDOSO, M. I.; FERNANDES, C. T. F. Flora bacteriana aeróbica conjuntival de cães clinicamente normais. Arquivo da Faculdade de Veterinária UFRGS, n. 17, p. 53-57, 1989.

GALERA, P. D.; AVILA, M. O.; RIBEIRO, C. R.; SANDOS, F. V. Estudo da microbiota da conjuntiva ocular de macacos-prego (Cebus apella - LINNAEUS, 1758) e macacos bugio (Alouatta caraya - HUMBOLDT, 1812), provenientes do reservatório de Manso, MT, Brasil. Arquivo do Instituto de Biologia, v. 69, n. 2, p. 33-36, 2002.

GRAHAM, J. E.; MOORE, J. E.; JIRU, X.; MOORE, J. E.; GOODALL, E. A.; DOOLEY J. S. G.; HAYES, V. E. A.; DARTT, D. A.; DOWNES, C. S.; MOORE, T. C. B. Ocular pathogen or commensal: A PCR-based study of surface bacterial flora in normal and dry eyes. Investigative Ophthalmology \& Visual Science, v. 48, n. $12,2007$.

HAGHKHAH, M.; SARCHANI, A. A.; MOLAZEM, M. Conjunctival flora in normal dogs. On line Journal of Veterinary Research, v. 9, n. 2, p. 79-83, 2005.

HOEKSTRA, K. A; PAULTON, R. J. Clinical prevalence and antimicrobial susceptibility of Staphylococcus aureus and Staph. intermedius in dogs. Journal of applied microbiology, v. 93, n. 3, p. 406-413, 2002.

JONES, W. G. A preliminary report of the flora in health and disease of the external ear and conjunctival sac of the dog. Journal of American Veterinary Medical Association, v. 944, n. 127, p. 442-444, 1955.

KUDIRKIENE, E.; ZILINSKAS, H.; SIUGZDAITE, J. Microbial flora of the dog eyes. Lituania. Veterinarija ir zootechnika, v. 34, n. 56, 2006.

MOELLER, C. T. A.; BRANCA, B. C.; YU, M. C. Z.; FARAH, M. E.; SANTOS, M. A. A.; HÖFLING-LIMA, A. L. Evaluation of normal ocular bacterial flora with two different culture media. Canine Journal Ophthalmology, v. 40, n. 4, 2005.

PRADO, M. R.; ROCHA, M. F. G.; BRITO, E. H. S.; GIRÃO, M. D.; MONTEIRO, A. J.; TEIXEIRA, M. F. S.; SIDRIM, J. J. C. Survey of bacterial microorganisms in the conjuntival sac of clinically normal dogs and dogs with ulcerative keratitis in Fortaleza, Ceara, Brazil. Veterinary Ophthalmology, v. 8, n. 1, p. 33-37, 2005.

PRADO, M. R.; BRITO, E. H. S.; GIRÃO, M. D.; 
SIDRIM, J. J. C.; ROCHA, M. F. G. Identification and antimicrobial susceptibility of bacteria isolated from corneal ulcers of dogs. Arquivo Brasileiro de Medicina Veterinária e Zootecnia, v. 58, n. 6, p. 1024-1029, 2006.

SANTOS, L. G. F.; ALMEIDA, A. B. P. F.; SILVA, M. C.; OLIVEIRA, J. T.; DUTRA, V.; SOUZA, V. R. F. Microbiota conjuntival de cães hígidos e com afecções oftálmicas. Acta Scientiae Veterinariae, v. 2, n. 37, p.165-169, 2009.

SWINGER, R. L.; LANGAN, J. N.; HAMOR, R. Ocular bacterial flora, tear production and intraocular pressure in a captive flock of Humboldt penguin (Spheniscus humboldti). Journal of Zoo and Wildlife Medicine, v.40, n. 3 , p. $430-436,2009$.

TUNTIVANICH, P.; SOONTORNVIPART, K.;
TUNTIVANICH, N.; WONGAUMNUAYKUL, S.; BRIKSAWAN, P. Schirmer tear test in clinically normal Asian elephants. Veterinary Research Communications, v. 26, n. 4, p. 297-299, 2002.

UESUGUI, E.; CYPEL-GOMES, M. C.; ATIQUE, D.; GOULART, D. G.; GALLUCCI, F. R.; NISHIWAKIDANTAS, M. C.; DANTAS, P. E. C. Identificação laboratorial dos patógenos oculares mais freqüentes e sua suscetibilidade in vitro aos agentes antimicrobianos. Arquivo Brasileiro de Oftalmologia, n. 65, p. 339-342, 2002.

WANG, L.; PAN, Q.; ZHANG, L.; XUE, Q.; CUI, J.; QI, C. Investigation of bacterial microorganisms in the conjuntival sac of clinically normal dogs and dogs with ulcerative keratitis in Beijing, China. Veterinary Ophthalmology, v. 11, n. 3, p. 145-149, 2008. 